\title{
Os Rostos Apagados: um Estudo de Caso sobre a Inclusão de Alunos do Campo
}

\section{Pós-graduanda em Gestão de Currículo na \\ Diovana Santos dos Santos Formação Docente na Universidade Estadual do Rio Grande do Sul, Bagé, RS, Brasil \\ E-mail: santosdiovana71@gmail.com \\ Professora na Universidade Estadual do Rio \\ Veronice Camargo da Silva Grande Do Sul, Unidade Bagé. Doutora em Letras. \\ E-mail: veronice-silva@uergs.edu.br \\ Autor correspondente: Pós-graduanda em Gestão de Currículo na Formação Docente na \\ Gabriela de Moraes Chaves Universidade Estadual do Rio Grande do Sul, Bagé, RS, Brasil.}

E-mail: gabinhadp@hotmail.com

Recebido em: 23 maio 2016. Revisado: 11 mar. 2017. Aceito: 11 mar. 2017. DOI: http://dx.doi.org/10.21674/2448-0479.32.286-314

\section{Resumo}

O propósito deste estudo foi identificar até que ponto a escola pública está preparada para atender a diversidade cultural dos estudantes sem "apagar" seus rostos e sua cultura. Dentre as diversas culturas presentes em uma escola, escolhemos os alunos oriundos da educação do campo. Tomamos como Lócus uma escola da zona urbana de Dom Pedrito-RS e partindo do conhecimento da presença de alunos que residem na zona rural do nosso município e frequentam uma escola da zona urbana. As bases teóricas desta pesquisa 
tomaram como referências principais Veiga (2002), Sacristán (1999, 2000), e as Diretrizes Operacionais para a Educação do Campo (1996). Para a elaboração deste trabalho, escolhemos como lócus uma escola pública localizada na cidade de Dom Pedrito, Rio Grande do Sul. O desenvolvimento da pesquisa teve uma abordagem qualitativa para uma melhor compreensão da realidade escolar analisada. Esta pesquisa caracteriza-se como bibliográfica, documental e, ainda, como um estudo de caso. As análises dos dados evidenciam que existe a necessidade de aproximar o conteúdo da realidade dos alunos. Percebemos com este trabalho, a importância da renovação do PPP nas escolas para que os "rostos dos alunos" não sejam apagados.

Palavras-chave: Currículo escolar. Formação de Currículo. Inclusão social. Educação do Campo.

\section{Abstract \\ The Faces Off: One Case Study on the Inclu- sion of Field Students}

The purpose of this study was to identify the extent to which the public school is prepared to meet the cultural diversity of students without "delete" their faces and their culture. Among the various cultures present in a school, choose students from the education field. We take as a Locus of urban school of Dom Pedrito (RS) and assuming knowledge of the presence of students residing in the countryside of our municipality and attend a school in the urban area. The theoretical bases of this research took over as main references Veiga (2002), Sacristán $(1999,2000)$, and Operational guidelines for field education (1996). The methodological approach was based on quali- 
tative research of bibliographical nature documentary analysis, being as corpus of analysis the pedagogical political project of the school, some observations and informal interviews with teachers, students and direction. The analyses of the data show that, teachers have knowledge of the cross-cutting is-sues and that there is the need to bring the contents of the reality of the students. We realize with this work the importance of renewal of the project in the schools so that the faces of the students are not deleted and the reflections that even back in your organization.

Keywords: School curriculum. Training curriculum. Social inclusion. Field education.

\section{Introdução}

Este trabalho propõe analisar e discutir como é tratada e vista a educação do campo na zona urbana do município de Dom PedritoRS. Essa necessidade parte do conhecimento da existência de alunos que residem na zona rural e frequentam a escola, lócus da presente pesquisa, que fica na zona urbana. Para o desenvolvimento deste trabalho, procuramos alicerce nas Leis da Educação do Campo visto que a realidade dos discentes que moram na zona rural é distinta dos que vivem no meio urbano. São alunos oriundos de classes multiseriadas e que possuem, muitas vezes, problemas com o transporte por falha mecânica do ônibus escolar ou, ainda, devido às condições de estrada nos períodos de chuva intensa. Esses problemas, dentre outros, interferem no processo de ensinoaprendizagem.

Dessa maneira, utilizamos entre aspas o termo "rostos apagados" fazendo menção a estes alunos que se deslocam todos os Rev. Elet. Cient. UERGS, v. 3, n. 2, p. 286-314, 2017 
dias para vir à cidade estudar, muitas vezes, em busca de algo que não encontram na escola. Pretende-se, portanto, compreender, com foco no Projeto Político Pedagógico (PPP), se realmente eles possuem seus rostos apagados no currículo escolar. Esta pesquisa torna-se relevante, por procurar conhecer a realidade escolar dos alunos, o ponto de vistas dos professores que atuam na rede pública e ministram aulas para estes alunos.

Posto isso, queremos observar como é tratada a educação do campo, quais são suas dificuldades e se os conteúdos desenvolvidos fogem da sua realidade de vida. Convém ressaltar que cada região possui suas peculiaridades, sendo assim, trabalhos como este que analisam a realidade de uma região como a nossa que a educação do campo é integrada por filhos de trabalhadores rurais e colonos, são importantes para seu real significado e importância.

Este trabalho torna-se relevante na medida em que tomamos conhecimento sobre a realidade do nosso município. Afinal, o Projeto Político Pedagógico da escola está atualizado? Contempla em sua proposta metodológica temas como Educação do Campo? Ainda, como os professores abordam em sala de aula a questão da estrutura fundiária na região, em especial o fato de haver a concentração de terra e uma grande maioria de trabalhadores como empregados e sem terras? Como os professores tratam o tema desenvolvimento e seus benefícios com o atual modelo? Que visão os docentes têm sobre do uso de novas tecnologias no meio rural e, ainda, que tipo de progresso essas novas tecnologias trouxeram para os grandes e pequenos proprietários rurais? Estes questionamentos, certamente, ajudarão a refletir como a educação do campo é tratada, além de provocar reflexões aos envolvidos no processo.

Para responder a esses questionamentos, analisamos, inicialmente, o Projeto Político Pedagógico da escola, além de conversar Rev. Elet. Cient. UERGS, v. 3, n. 2, p. 286-314, 2017 
com a diretora da Escola e aplicar um questionário aos docentes. No âmbito escolar, com relação ao conceito do que realmente é currículo, não há um consenso entre os principais autores ligados à educação o que nos permite, então, uma reflexão sobre os diferentes sentidos e significados do que ele realmente seja.

Sacristán (2000) conceitua currículo como:

Um conjunto de conhecimentos ou matérias a serem superadas pelo aluno dentro de um ciclo - nível educativo ou modalidade de ensino é a acepção mais clássica e desenvolvida; o currículo como programa de atividades planejadas, devidamente sequencializadas, ordenadas metodologicamente tal como se mostram num manual ou num guia do professor; o currículo, também foi entendido, às vezes, como resultados pretendidos de aprendizagem; o currículo como concretização do plano reprodutor para a escola de determinada sociedade, contendo conhecimentos, valores e atitudes; o currículo como experiência recriada nos alunos por meio da qual podem desenvolver-se; o currículo como tarefa e habilidade a serem dominadas como é o caso da formação profissional; o currículo como programa que proporciona conteúdos e valores que os alunos melhorem a sociedade em relação à reconstrução social da mesma. (SACRISTÁN, 2000, p.14)

Nesta segunda concepção o autor aborda outros fatores importantes como a formação de professores. Pode-se entender a partir dessa concepção que o currículo excede o aspecto da formalidade e se expressa, também, por meio da prática.

Logo, o currículo é a união das práticas administrativas, políticas, institucionais, econômicas junto às práticas didáticas, além de ser um artefato cultural, como afirmam os autores Moreira e Silva (1997, p. 8):

Um artefato social e cultural. Isso significa que ele é colocado na moldura mais ampla de suas determinações sociais, de sua história, de sua produção contextual. O currículo não é um elemento inocente e neutro de transmissão desinteressada do conhecimento social. O currículo está implicado em relações de poder, o currículo transmite visões sociais particulares e interessadas, o currículo produz identidades individuais 
e sociais particulares. O currículo não é um elemento transcendente e atemporal - ele tem uma história, vinculada às formas específicas e contingentes de organização da sociedade e da educação.

E como uma construção cultural, o currículo deveria ser refletido por todos os educadores no ambiente escolar, focando na valorização da identidade dos seus discentes e assim teríamos um currículo "capaz de incorporar o pluralismo cultural demanda um contexto democrático de decisões sobre os conteúdos de ensino, no qual os interesses de todos tenham a possibilidade de ser representados" (MOREIRA; SILVA, 1999, p.76).

Ainda neste contexto cultural do currículo, Arroyo (2011) ressalta que o currículo ignora, esconde, trata como se não existisse a história intelectual de cada sujeito, os coletivos populares e enfatiza que devemos:

\footnotetext{
Reconhecer que cada experiência tem como autores sujeitos pessoais e coletivos reais que não têm uma autoria solitária, mas estão entrelaçados em relações sociais, raciais, de gênero, de cidade, periferia, campo, de orientação sexual, de opções políticas e morais (ARROYO, 2011, p.149).
}

Por conseguinte, o currículo crê na consolidação dos fins culturais e sociais quando segue o pressuposto que o currículo é um processo de construção a partir da realidade, cultura e do mundo social. Portanto, seria necessário que os educandários e as salas de aula se organizassem para receber esses alunos que possuem suas peculiaridades culturais marcadas.

Embora exista uma pluricidade de culturas dentro do ambiente escolar, com a "flexibilidade" curricular pode-se fazer uma troca de vivências e, consequentemente, a interação cultural formando uma produção cultural dentro da escola. Desta forma, não estaríamos negando "o direito à produção intelectual, cultural, ética, estética, mas de incorporar outras leituras de mundo, outros saberes de si 
mesmos" (ARROYO, 2011, p. 42), mas sim, refletir o currículo como uma prática curricular como um ambiente de negociação entre a cultura escolar e a cultura da escola.

Segundo Silva (1999, p. 14) o currículo está:

Inextricavelmente, centralmente, vitalmente, envolvido naquilo que somos, naquilo que nos tornamos: na nossa identidade, na nossa subjetividade. Talvez possamos dizer que, além da questão do conhecimento, o currículo é também uma questão de identidade.

Portanto, o currículo está ligado às questões de identidades de cada sujeito que faz parte do educandário. Assim, os currículos multiculturais ligam as várias identidades dos seus sujeitos como neste caso, se pode ligar não apenas os alunos que vem da zona rural estudar na cidade, mas trazer a identidade cultural do nosso município que possui a sua fonte de renda principal a pecuária e as plantações, como pode ser visto a seguir.

O Projeto Político Pedagógico (PPP) do educandário é o instrumento no qual é demonstrado à autonomia da escola, de sua competência de tracejar sua própria identidade. Veiga (2002, p.14) afirma que o projeto político-pedagógico:

Está relacionado com a organização do trabalho pedagógico em dois níveis: na organização da escola como um todo e na organização da sala, incluindo sua relação com o contexto social imediato, procurando preservar a visão de totalidade. Nesta caminhada será importante ressaltar que o Projeto Político Pedagógico busca a organização do trabalho pedagógico e conquista da autonomia da escola.

Nesse sentido, o PPP é o planejamento do que se tem a intenção de fazer, de realizar dentro e fora da escola visando um meIhoramento na qualidade do ensino. Desta forma, a construção de um Projeto Político Pedagógico se torna crucial para a estrutura 
escolar e deve ser construído por todos os integrantes da escola, visto que o projeto compete à operacionalização do planejamento da instituição de ensino.

O Projeto Político Pedagógico perpassa as funções burocráticas porque reflete as diferentes realidades do cotidiano escolar. $\mathrm{Ou}$ seja, o PPP cuida, além das questões pedagógicas, também de questões políticas, de gestão, administrativas e não se deve colocar nele toda a responsabilidade que é a produção de do currículo da escola.

Para Veiga (2002, p.11), o PPP necessita ter:

a) ser um processo participativo de decisões; b) preocupar-se em instaurar uma forma de organização de trabalho pedagógico que desvele os conflitos e as contradições; c) explicitar princípios baseados na autonomia da escola, na solidariedade entre seus agentes educativos e no estímulo à participação de todos no projeto comum e coletivo; d) conter opções explícitas na direção da superação de problemas, no decorrer do trabalho educativo voltado para uma realidade específica; e) explicitar o compromisso com a formação do cidadão. No que tange à execução: a) nascer da própria realidade, tendo como suporte a explicitação das causas dos problemas e das situações nas quais tais problemas aparecem; b) ser exequível e prever as condições necessárias ao desenvolvimento e à avaliação; c) implicar uma ação articulada de todos os envolvidos com a realidade da escola; e d) ser construído continuamente, pois, como produto, é também processo, incorporando ambos numa interação possível.

Por conseguinte, a elaboração de um PPP demanda continuidade, por tratar-se de diversas realidades presentes na escola. Anualmente, entram e saem alunos do educandário, logo, o público atingido, renova-se a cada ano. Dessa forma, "é preciso entender o Projeto Político Pedagógico da escola como uma reflexão de seu cotidiano" (VEIGA, 2002, p. 33).

Alarcão (2003, p.36) reflete, ainda, sobre a reciclagem do PPP: 
As escolas ainda não compreenderam que também elas têm de se repensar. Permanecem na atitude negativa de se sentirem defasadas, mal compreendidas e mal amadas, ultrapassadas, talvez inúteis. Quedam-se à espera que alguém as venha transformar a si próprias. Por dentro. Com as pessoas que as constituem: professores, alunos, funcionários. Em interação com a comunidade circundante.

Destacamos a importância das instituições possuírem um Projeto Político Pedagógico atualizado e democrático para o sucesso do funcionamento da escola tendo em vista que as mudanças sociais e culturais, por exemplo, colaboram com as transformações dos indivíduos. Consequentemente, torna-se necessário rever o PPP. Ou seja, a escola não pode ser algo estático no tempo; ela possui transformações em suas concepções de acordo com a necessidade que os sujeitos apresentam no presente vivido tal como é possível evidenciar na fala de Camozzato e Costa (2013, p.179):

Indicam e expressam, em cada tempo-espaço, objetivos diferenciados, uma vez que estão articuladas aos discursos vigentes. As condições para atuar sobre si mesmo e se remodelar constantemente a partir das demandas e exigências sociais foram destacadas para que consigamos compreender que um deslocamento desse tipo está em sintonia com as linhas de força que atuam na sociedade em cada tempoespaço.

De tal modo, o Projeto Político Pedagógico vai muito além da discrição da organização escolar, ele reflete sobre as metas futuras, sobre as práticas pedagógicas e de como elas refletiram na aprendizagem dos alunos e como se pode constatar na fala de Camozzato e Costa (2013), existe a necessidade da escola e dos profissionais que atuam no educandário adaptarem-se às necessidades da sociedade ao qual se encontram em continua transformação. Isto é, um PPP atual trabalha o hoje, pensando no amanhã, porém, com os 
"pés no chão" e sempre visando à realidade do aluno, à sociedade atual e às reais necessidades de ambos- alunos e sociedade - $\mathrm{e}$ assim aproximando conteúdos do cotidiano e tentando fazer a escola um ambiente acolhedor e motivador de saberes.

$\mathrm{Na}$ educação, um dos aspectos discutidos ultimamente e que há tempos está em discussão, é a necessidade de abordá-la levando em consideração as diversas realidades dos nossos alunos:

O debate da relação campo-cidade perpassa todas as reflexões de Educação do Campo. Por muito tempo a visão que prevaleceu na sociedade, continuamente majoritária em muitos setores, é a que considera o campo como lugar atrasado, do inferior, do arcaico. Nas últimas décadas consolidou-se um imaginário que projetou o espaço urbano como caminho natural único do desenvolvimento, do progresso, do sucesso econômico, tanto para indivíduos como para a sociedade. (CALDART, 2004, p 11).

Muitas vezes os pais preferem que os filhos desloquem-se para a cidade estudar por considerar que o aprendizado dos seus fiIhos será melhor do que na zona urbana, além, ainda, da preocupação por parte desses pais em relação à formação dos docentes que estão nas instituições rurais. Segundo o Instituto Nacional De Pesquisa Educacionais Anísio Teixeira (2007, p. 33):

O nível de escolaridade dos professores revela, mais uma vez, a condição de carência da zona rural. No ensino fundamental de $1^{\text {a }}$ a $4^{a}$ série, apenas $21,6 \%$ dos professores das escolas rurais têm formação superior, enquanto nas escolas urbanas esse contingente representa $56,4 \%$ dos docentes. $O$ que é mais preocupante, no entanto, é a existência de 6.913 funções docentes sendo exercidas por professores que têm apenas o ensino fundamental e que, portanto, não dispõem da habilitação mínima para o desempenho de suas atividades. A maioria desses professores leigos atua nas Regiões Nordeste e Norte. 
À vista disso, justifica-se a preocupação que alguns pais possuem sobre a educação do campo e o porquê submetem seus filhos a enfrentarem horas na estrada deslocando-se até uma escola na zona urbana. Na cidade, objeto da pesquisa, segundo o Censo 2010 do Instituto Brasileiro de Geografia e Estatística (IBGE), possui 35.275 habitantes na zona urbana e 3.641 habitantes na zona rural, totalizando $9,36 \%$ da população residindo na zona rural do nosso município. Como principal fonte de renda pecuária e agricultura. Por isso, olhar para a educação na zona rural dessa cidade, torna-se necessário já que quase $10 \%$ da posso população reside na campanha.

Dados apontam que esse município, infelizmente, não possui muitas escolas na zona rural de acordo com a proporção do territorial ao qual é extensa. Consequentemente, o deslocamento dos jovens para a zona urbana é a alternativa encontrada pela prefeitura para que os estudantes sigam frequentando instituições de ensino e, para isso, fornecem o transpor-te público gratuito aos mesmos. Logo, trabalhar aspectos envolvendo a educação do campo em escolas urbanas torna-se relevante, visto o expressivo número de habitantes da zona rural que vem estudar na cidade.

$E$, por isso, os defensores da educação do campo apontam que "[...] a educação desses diferentes grupos tem especificidades que devem ser respeitadas e incorporadas nas políticas públicas e nos projetos pedagógicos" (BRASIL, 2004, p. 17).

Em relação a trabalhar esses aspectos Viana (1933, p.108) afirma que:

A educação, portanto, é concebida como um processo que envolve todas as experiências das crianças, experiências adquiridas quer dentro, quer fora da escola. Assim, seja na cidade, seja na zona rural, o conhecimento da vida do aluno fora da escola é de real importância, isto porque os objetivos educacionais só serão alcançados quando as experiências, 
as atividades, os problemas vitais das crianças fora se refletirem nas atividades de dentro da escola, como parte integrante de um programa unificado de trabalho.

Mediante o exposto, o professor necessita educar para a diversidade, contudo, isso não denota apenas perfilhar o outro como desigual, mas elucubrar sobre as relações e os direitos de todos. $\mathrm{E}$ o educandário é o ambiente sociocultural em que as distintas analogias se encontram e se constituem, caracterizando-se, por conseguinte, como um dos ambientes mais importantes para se educar com vias a reverência à diferença.

No que se diz respeito à Educação do Campo, Fernandes (2002, p. 97) afirma que:

A Educação do Campo é um conceito cunhado com a preocupação de se delimitar um território teórico. Nosso pensamento é defender o direito que uma população tem de pensar o mundo a partir do lugar onde vive, ou seja, da terra em que pisa, melhor ainda: de sua realidade. Quando pensamos um mundo a partir do lugar onde não vivemos, idealizamos um mundo, vivemos um não lugar. Isso acontece com a população do campo quando pensa o mundo e, evidentemente, o seu próprio lugar a partir da cidade.

Isto é, trabalhar na sala de aula temas que envolvam a realidade dos alunos tornam-se cruciais, não apenas para o aluno do campo, mas o da cidade que possui sua própria realidade social e/ou familiar.

Neste contexto Sacristán pondera que:

O mais importante num processo de mudança curricular não é um novo currículo materializado em papel, tabelas ou gráficos. O currículo não se traduz em uma realidade pronta e tangível, mas na aprendizagem permanente de seus agentes, que leva a um aperfeiçoamento contínuo da ação educativa. [...] a reforma a que aqui se propõe será tanto mais eficaz quanto mais provocar os sistemas, escolas e professores para a reflexão, análise, avaliação e revisão de suas práticas, 
tendo em vista encontrarem respostas cada vez mais adequadas às necessidades de aprendizagem de nossos alunos. (SACRISTÁN 2000, p. 140).

Quando focamos nosso olhar para esses alunos que enfrentam o desafio diário para chegar até a escola, entendemos os números alarmantes de crianças que residem na zona rural e estão fora da escola. Sobre esses dados Silva et al. (2006, p. 71) revela que:

Nas zonas rurais, $6 \%$ das crianças de 7 a 14 anos estão fora da escola, comparado a $3 \%$ nas zonas urbanas. Dos jovens de 15 a 18 anos, 65,3\% estão matriculados, mas $85 \%$ deles apresentam defasagem de idade/série. Nas zonas urbanas a taxa de matrícula desse mesmo grupo etário é de $77,1 \%$, sendo que $65 \%$ apresentam defasagem idade série. O número médio de anos de escolarização da população adulta (com 25 anos de idade ou mais) residente na zona rural é de apenas três anos, comparado há 6,5 anos nas áreas urbanas. Um terço $(36 \%)$ da população adulta que vive no meio rural é considerada analfabeta.

Ao observarmos esses números, percebemos o quanto é preocupante a situação da educação do/no campo. Nesse contexto, Egami et al. (2008, p. 3) afirma que:

Quanto maiores são as barreiras físicas e mais baixas a situação financeira do aluno, maior é a dependência do transporte para se chegar à escola. $\mathrm{O}$ não fornecimento de um meio de transporte pode acarretar no não comparecimento do professor e de muitos estudantes às aulas.

Assim sendo, metodologias que ajudem o aluno se interessar por as questões propostas no dia a dia em sala de aula tornam-se de vital importância para que estes números mudem de forma significativa.

Como se pode notar nas Diretrizes Operacionais para a Educação Básica, educação do campo é tratada como: 
Educação rural na legislação brasileira tem um significado que incorpora os espaços da floresta, da pecuária, das minas e da agricultura, mas os ultrapassa ao acolher em si os espaços pesqueiros, caiçaras, ribeirinhos e extrativistas. O campo neste sentido é mais que um perímetro não urbano, é um campo de possibilidades que dinamizam a ligação dos seres com a própria produção das condições de existência social e com as realizações da sociedade humana (CONSELHO NACIONAL DE EDUCAÇÃO, 2002, p. 35).

Em virtude disso, as Diretrizes Operacionais para a Educação Básica nas Escolas do Campo, abordam verdadeiramente o conceito de educação do campo, rompendo o conceito errôneo da definição dos espaços que a Educação do Campo engloba, ou seja, ela elucida que a educação do campo não se trata apenas de limites geográficos e vai muito mais além. Recai, principalmente, no papel do 'ser' professor. Logo, segundo (ARROYO, 2011, p. 52):

ser docente - educador não é ser fiel a rituais preestabelecidos, mas se guiar pela sensibilidade para o real, à vida real, sua e dos educandos é criar, inventar, transgredir em função de opções políticas, éticas.

Sendo assim, é de vital importância que os professores conheçam seus alunos e que, a partir disso, planejem seus conteúdos de acordo com a realidade dos mesmos, com o intuito de despertar o desejo de aprender e que esses estudantes não desistam em meio às dificuldades do dia a dia.

\section{Metodologia}

De acordo com a metodologia de pesquisa proposta por Vergara (1998), podemos classificar a presente investigação como bibliográfica, tendo em vista que buscamos as Leis, Decretos e materiais entender os conceitos sobre a formação do currículo e a impor- 
tância de formá-lo levando em conta a realidade dos alunos. Consideramos uma pesquisa Documental, uma vez que se utilizou de documentos oficiais: o Projeto Político Pedagógico da escola.

A primeira parte metodológica constitui-se pela pesquisa qualitativa bibliográfica:

\begin{abstract}
A pesquisa bibliográfica é feita a partir do levantamento de referências teóricas já analisadas, e publicadas por meios escritos e eletrônicos, como livros, artigos científicos, páginas de web sites. Qualquer trabalho científico inicia-se com uma pesquisa bibliográfica, que permite ao pesquisador conhecer o que já se estudou sobre o assunto. Existem, porém pesquisas científicas que se baseiam unicamente na pesquisa bibliográfica, procurando referências teóricas publicadas com o objetivo de recolher informações ou conhecimentos prévios sobre o problema a respeito do qual se procura a resposta (FONSECA, 2002, p. 32).
\end{abstract}

Em suma, ao optarmos por este modelo de pesquisa pretendemos entender com mais profundidade o conceito de currículo e a importância da inclusão dos alunos do campo.

Para a elaboração deste trabalho, escolhemos como lócus uma escola pública localizada na cidade de Dom Pedrito, Rio Grande do Sul. Para o desenvolvimento da pesquisa proposta, por questões éticas, optamos por não nomear a instituição pesquisada. $O$ desenvolvimento da pesquisa teve uma abordagem qualitativa para uma melhor compreensão da realidade escolar analisada.

Esta pesquisa caracteriza-se do mesmo modo como um estudo de caso. Yin (apud ROESCH, 1999, p. 155), no que se refere ao conceito de estudo de caso, diz que "é uma estratégia de pesquisa que busca examinar um fenômeno contemporâneo dentro de seu contexto".

Neste caso, nossa pesquisa analisa apenas uma escola urbana da cidade de Dom Pedrito que possui alunos que se deslocam todos os dias da zona rural para estudar na zona urbana.

Desse modo, seguimos este preceito por acreditar que: 
o delineamento se fundamenta na ideia de que a análise de uma unidade de determinado universo possibilita a compreensão da generalidade do mesmo ou, pelo menos, o estabelecimento de bases para uma investigação posterior, mais sistemática e precisa (GIL, 1991, p. 79).

Desta maneira, o Estudo de Caso visa adequar à vivência da realidade, assim podemos analisar mais a fundo se a inclusão dos alunos oriundos do campo.

O instrumento escolhido foi um questionário semiestruturado aplicado a cinco docentes das disciplinas de Português, Ciências, Matemática, Geografia e História. Conversamos previamente com cada professor, explanamos a finalidade da nossa pesquisa e entregamos o questionário impresso a cada um deles. Alguns pediram para responder em casa por causa da disponibilidade de tempo para dedicar-se a responder nossos questionamentos.

Nem todos os professores responderam às questões. O professor de história não quis responder, justificou não ter compreendido nossas perguntas e pediu ao diretor daquele educandário que devolvesse o questionário. Ressaltamos que o professor de ciências apenas respondeu as três perguntas e o professor de português, respondeu de forma evasiva, não dando aos pesquisadores dados para uma reflexão mais profunda. Diante disso, foram analisadas as repostas dos professores de geografia, matemática e ciências.

\section{Resultados e Discussão}

A escola, objeto de estudo, foi fundada em catorze de fevereiro de mil novecentos e setenta e nove (14/02/1979). O primeiro PPP construído foi registrado no dia vinte quatro de março de mil novecentos e noventa e cinco (24/03/1995), ou seja, a escola possui um PPP há vinte (20) anos. O PPP vigente foi atualizado no ano de 
2009 e, conforme consta no final do mesmo, foi elaborado com a participação de todo o corpo docente e Conselho Escolar.

A referida escola atende a educação básica, da educação infantil ao nono ano (ou como previsto no PPP, oitava série). Está localizada no município de Dom Pedrito-RS e abrange uma comunidade diversificada, possuindo alunos residentes na zona urbana e da zona do nosso município. O PPP da escola apresenta sua estrutura escolar: dados de identificação quanto ao nome da escola, o decreto de criação, sua localização no município, os níveis de escolaridade, números de professores, alunos e funcionários de quando foi fundada.

Com relação às expectativas, o documento deixa claro que o desejo é que a mesma tenha professores, alunos e comunidade motivados e participativos e que todos exerçam seus direitos e deveres. Tem como filosofia, a Solidariedade.

O documento apresenta metas a curto, médio e longo prazo. De todas as metas, duas envolvem investimento humano: conseguir um profissional para atender alunos com dificuldades de aprendizagem no turno inverso e outro profissional para auxiliar professores e alunos no laboratório de aprendizagem. As demais metas são de ordem física ou material. Desde calçamento, muro, data show até construção de salas e auditório. Nesse sentido, Viana (2002) ressalta a importância de que no PPP deva buscar a organização do trabalho pedagógico e a conquista de sua autonomia o que para isso, torna-se importante organizar a escola como um todo, o que inclui a relação do trabalho pedagógico com o contexto social.

Quanto aos objetivos, o documento apresenta um objetivo geral que é "desenvolver uma prática Educativa onde a formação do educando aconteça de maneira plena e de qualidade, fazendo com que cada pessoa inserida na escola desenvolva seu trabalho bus- 
cando esse objetivo". Para atingir esse objetivo há uma preocupação de seja trabalhado com toda a comunidade escolar. Na sequência, elenca um objetivo específico ao aluno, outro ao professor e, ainda, outro à sociedade. Todos eles priorizam participação, comprometimento, cumprimentos das regras, sem deixar de lado a solidariedade e conhecimento. No objetivo ao professor, há uma preocupação de que o mesmo sempre busque aperfeiçoar sua prática pedagógica e que seja um profissional que atenda as peculiaridades de cada aluno.

O PPP propõe uma metodologia voltada a uma prática pedagógica dinâmica, audaciosa e inovadora para que todo o conhecimento trabalhado seja "informado e experiência", sempre proporcionando discussão e debate. Reforça-se aqui a importância de que esse documento seja atualizado (CAMOZZATO; COSTA, 2013) em seu tempo-espaço, uma vez que objetivos tornam-se diferenciados, porque precisam estar articuladas aos discursos vigentes.

A avaliação segue o Regimento escolar com convenções: A Atingiu. AP - Atingiu Plenamente e NA - Não Atingiu. Para tanto, prevê que toda a prática pedagógica seja baseada em Habilidades e Competências. Tanto na Educação Infantil como nos anos iniciais (o documento apresenta como séries iniciais), são priorizados 5 focos: produção de texto, escrita ortografia, leitura e raciocínio matemático. Ressalta, ainda, que nas séries finais o foco do trabalho é com base na Matriz de Habilidades. Como instrumento de avaliação, o PPP prevê testes orais, escritos, pesquisas. A escola tem previsto em seu calendário, uma semana em cada bimestre para realização dos testes escritos, com dia e hora marcados, o que a escola caracteriza como semana de provas. São considerados, ainda, para fins de avaliação, trabalhos individuais, em grupo, diálogos, debates, exposições de trabalhos. 
Como plano de ação, o documento assegura que o trabalho seja realizado em equipe para melhorar a gestão escolar no sentido de partilhar as responsabilidades da direção da escola com pais, alunos, professores e funcionários. Na sequência, o PPP apresenta o código de regras, tais como os direitos e deveres do professor, ainda, o que é vedado ao professor como, por exemplo, "ocupar-se em classe de assuntos estranhos á atividade educativa" ou "adotar metodologia de ensino e avaliação superados, incompatíveis à orientação pedagógica". Ao aluno também são apresentados os direitos, deveres e o que não é permitido ao mesmo, tais como participar de brigas, entrar ou sair sem a permissão do professor. Também são apresentadas quais situações o aluno pode ser penalizado, bem como as sanções como repreensão verbal, por escrito, indenização em caso de depredação e, por último, suspensão de até 3 dias.

O PPP apresenta atividades previstas (interséries, gincanas, homenagens, etc.), projetos (oficinas, campanhas, projetos de leituras, etc.). No que se diz respeito aos projetos desenvolvidos pela escola, encontramos uma lista de "projetos desenvolvidos", como mencionado anteriormente, porém ao questionar se todos eles estão sendo praticados, a diretora revela que não, com exceção da feira de ciências da escola. Em contraponto, a isto, a gestora revela 0 projeto "Mais Educação" que estava sendo desenvolvido na escola e que foi implantado no final de dois mil e dois, mas não está no PPP da escola. Mais uma vez reforçamos que o PPP precisa ser construído continuamente (VEIGA, 2000).

No final, o PPP elenca inúmeras recomendações que considera importantes para garantir o sucesso do trabalho escolar, tais como dicas pedagógicas aos professores, dicas aos pais, aos alunos, regras de convivência. O mesmo é finalizado com uma lista de possíveis ações que o professor pode dar conta para garantir a edu- 
cação de qualidade, tais como entrar alegre na sala de aula, cumprimente seus alunos, reze com seus alunos, reflita a melhor forma de avaliar, reflita sobre a prática pedagógica, dentre outras recomendações. Observa-se que o Projeto Político Pedagógico, apesar de ter os itens descritos, não apresenta uma base teórica que fundamente os aspectos filosóficos, sociológicos e epistemológicos.

Neste termo estrutural, com sua desatualização, não foi possível informar os números que compõem a formação escolar, visto que, segundo a própria diretora, desde a formação do PPP a escola "evolui e cresceu muito". No entanto, o documento não contempla adendos sobre a referida evolução. Em função dessa não atualização, não se pode informar, também, o número atual de professores, alunos e serventes. O projeto, por exemplo, não relata a mudança curricular que a escola sofreu em passar de série para anos, por exemplo.

Segundo a diretora da escola, o PPP está disponível para a consulta na secretária da escola. Reforça que embora não tenha sido feito uma reciclagem do documento, o mesmo é sempre discutido nas reuniões pedagógicas escolares. Alarcão (2003) reforça a importância de que as escolas precisam compreender que também têm de se repensar, se reciclar para não ficarem defasadas. O que lava a crer que esse caminho é revisão e atualização periódica do PPP para, inclusive, estar de acordo com os discursos vigentes (CAMOZZATO; COSTA, 2013). À medida que este trabalho ia recebendo formato e sentido, fortalecia-se cada vez mais a ideia de que o PPP deve ser discutido e devemos atualizá-lo para que integrantes da escola, atual ou futuro, conheçam o seu funcionamento, seja ele funcionário, professor, aluno ou pai/mãe de aluno.

O questionário aplicado aos docentes possui quatro perguntas de cunho dissertativo. São ressaltadas respostas consideradas rele- 
vantes para dar conta do objetivo proposto. No que se diz respeito à primeira questão sobre como é feita a abordagem da estrutura fundiária na região, em especial o fato de haver a concentração de terra e uma grande maioria de trabalhadores como empregados e sem terras, destaca-se a fala do professor de matemática:

\begin{abstract}
Minha disciplina é matemática e Dom Pedrito é a cidade dos extremos: grandes proprietários de terras, que conseguem os primeiros empréstimos e por isso plantam sempre no tempo certo e do outro lado pequenos proprietários que lutam com dificuldade para não perderem o que têm e uma grande maioria de trabalhadores empregados desses latifundiários e exsem-terra, porque hoje eles já têm seu pequeno pedaço para trabalhar. O que se pode fazer contra essa dura realidade? Professor do campo não tem que incendiar revoltas e sim incentivar seus alunos a estudar para saírem desse círculo vicioso de empregados dos "grandes" e sim terem condições de uma profissão independente ou de "quando formados", voltarem ao campo para ajudar os pais com técnicas novas a fim de tornarem suas pequenas propriedades mais produtivas (Professor de matemática).
\end{abstract}

Em sua fala inicial, o professor de matemática demonstra conhecimento sobre as questões que envolvem a realidade do nosso município. Porém, destaca-se de sua fala o fato de que ele coloca a responsabilidade dos temas voltados à educação do campo apenas para o docente que trabalha na zona rural do nosso município.

Deste modo, o professor deixa de trabalhar um tema transversal que aproxima o seu aluno da sua realidade. Os PCNs de Temas Transversais (BRASIL, 1998a, p. 57) ressaltam que o "significado da Matemática para o aluno resulta das conexões entre ela e os Temas Transversais, entre ela e o cotidiano e das conexões que ela estabelece entre os diferentes temas matemáticos". Assim sendo, o professor ao deixar de abordar esta temática, acaba prejudicando o processo de ensino e aprendizagem dos seus alunos no momento em que deixa de aproximá-lo a sua vida cotidiana. Outro 
ponto que deve ser ressaltado é a questão da fala do professor ao "jogar" a responsabilidade de temas relacionados ao campo apenas ao professor da zona rural. Mais uma vez buscamos nos PCNs o compromisso do trabalho docente com temas transversais ao afirmar que:

O compromisso com a construção da cidadania pede necessariamente uma prática educacional voltada para a compreensão da realidade social e dos direitos e responsabilidades em relação à vida pessoal e coletiva e a afirmação do princípio da participação política. Nessa perspectiva é que foram incorporados como Temas Transversais as questões de Ética, da Pluralidade Cultural, do Meio Ambiente, da Saúde, da Orientação Sexual e do Trabalho e Consumo (BRASIL, 1998b, p. 17).

Além disso, ao analisar mais profundamente a fala do docente, podemos notar um preconceito perante o aluno que reside na zona rural ou que os pais residam passando a ideia de retrocesso em relação aos habitantes da zona urbana. Munarim (2006, p. 20), retrata para a importância de ultrapassar a visão dicotômica que avalia a cidade como local de desenvolvimento e o rural como local de retrocesso, uma vez que as políticas públicas "voltadas ao meio rural são traçadas no sentido de extrair do campo o máximo de benefício em favor da vida na cidade, ou então, no sentido de urbanizar o espaço rural".

Neste sentido, o conhecimento da realidade do município feita pelo professor poderia ser vista como um tema transversal e assim ser trabalhado, já que como vêm pessoas oriundas da zona rural pode haver a possibilidade de que existem alunos que possuem pais granjeiros e ainda assim torna-se relevante à temática, visto que umas das principais fontes de renda vêm do campo.

Em contraponto à resposta do professor de matemática, o professor de ciências apenas relata os conteúdos desenvolvidos por Rev. Elet. Cient. UERGS, v. 3, n. 2, p. 286-314, 2017 
ele, mas sem aprofundar-se na resposta. Com relação ao questionamento "na sua concepção como é tratado o tema desenvolvimento e quem se beneficiaria com o atual modelo adotado na região da campanha", destacamos a fala do professor de geografia:

Poucos se beneficiam com o atual modelo. Os ricos talvez
são os mais beneficiados, porque para haver um desenvolvi-
mento existe necessidade de estrutura financeira (muitas ve-
zes utilizando financiamento bancário, etc.) O desenvolvimen-
to no meio rural não é tratado. (Relato do professor de geo-
grafia)

Observa-se aqui uma contradição entre o que é dito e o que é feito na prática pedagógica do docente na mediada em que o mesmo revela que trabalha diariamente com o livro didático, tendo em vista que foi possível constatar que o livro em questão apresenta temas que abordam o desenvolvimento rural, por exemplo, e temas que envolvem as relações de campo e cidade.

Ao retomar as expectativas do PPP, consta-se que os docentes não conhecem ou não têm claro quais são essas expectativas, pois o mesmo deixa claro que quer alunos e comunidade motivados e participativos e que todos exerçam seus direitos e deveres.

Em relação ao questionamento acerca da visão que eles têm sobre do uso de novas tecnologias no meio rural e, ainda, que tipo de progresso essas novas tecnologias trouxeram para os grandes e pequenos proprietários rurais, chama-nos atenção à resposta do professor de geografia que responde que percebe avanços, no entanto, não para todos os proprietários rurais e complementa "talvez para os grandes proprietários. Para os pequenos, acredito que só houve endividamento".

O docente em sua fala faz uma generalização de fracasso pelos trabalhadores/produtores com um valor aquisitivo baixo, revelando a noção de fracasso das suas aquisições tecnológicas. Ainda neste sentido, o professor de matemática concorda com a fala do Rev. Elet. Cient. UERGS, v. 3, n. 2, p. 286-314, 2017 
docente de geografia no seu discurso e destacando que "o beneficiário com o desenvolvimento e o uso de novas tecnologias é sempre o latifundiário, porque ele tem recursos próprios, não precisa esperar pelo governo". Logo, contatamos na fala desses professores, que o pequeno proprietário sempre tenderá ao fracasso e o grande proprietário sempre vai sair beneficiado com as tecnologias. Esta visão pessimista não foi argumentada através de exemplos e indícios que afirmassem que a sua visão é o que realmente acontece na zona rural. Então, salienta-se que essa visão não deveria ser tão generalizada já que muitas vezes a sua visão crítica aparece em seu discurso dentro da sala de aula e pode refletir, naturalmente, de forma negativa ao ser discutido esta temática em sala de aula.

Em relação à pergunta envolvendo as ações (atividades práticas) a serem desenvolvidas a partir do estudo sobre o modelo de desenvolvimento praticado na região, destacamos a fala do professor de matemática:

Sinceramente, não vejo porque bitolar os alunos para que fiquem sempre no campo. Acho que a escolha dever ser deles e para isso já existe escolas técnicas rurais para que estiver interessado em trabalhar no campo. Porém, no ensino fundamental, todos devem ter as mesmas oportunidades de aprendizagem. A função dos professores é ensinar e explicar a realidade, a escolha é deles sempre. (Relato do professor de Matemática).

\section{Conclusão}

Neste trabalho, examinamos como são tratadas as temáticas envolvendo a educação do campo em uma escola pública localizada na zona urbana da cidade de Dom Pedrito-RS que possui alunos que residem na zona rural e estudam naquele colégio.

Os dados revelam que o Projeto Político Pedagógico da escola analisada não está atualizado e não contempla em sua proposta 
metodológica temas como Educação do Campo. Apesar, de acordo com informações da diretora, o PPP ser colocado à disposição dos docentes, pode-se dizer que o mesmo está engavetado e, portanto, fora de discussões atuais e vigentes.

A escola, por sua vez, precisa ser vista como um espaço de articulação de novas ideias e novos desafios. Para tanto, seus pares devem estar preparados, abertos e dispostos a mudanças e o PPP, pode ser visto como um caminho possível para ensinar com qualidade, cumprindo sua função social e seu papel político institucional.

Sobre do uso de novas tecnologias no meio rural, os docentes têm a visão de que esse acesso é somente para os grandes proprietários. Destaca-se que faltam informações e discussões necessárias a esse respeito para uma boa proposta pedagógica. Mais uma vez coloca-se o PPP como possibilidade para superar essas questões.

De um modo geral os professores revelam ter conhecimento sobre a realidade do nosso município. Seus pontos de vistas são muito fechados e críticos, em especial a visão do professor de matemática que evidenciava domínio sobre os assuntos relativos à realidade rural e urbana do município e mesmo assim demonstrou certo preconceito sobre estas realidades. Constatou-se que não há preocupação por parte dos professores com relação a abordar em sala de aula a questão da estrutura fundiária na região.

No que se diz respeito à abordagem dos temas relativos à educação do campo, os professores relataram que não abordam esse tema, mesmo sabendo da existência de alunos que residem na zona rural e deslocam diariamente para estudar naquela instituição de ensino.

A educação não deveria ser vista como a do "campo" e da "cidade", assim como não deveria ser vista como partes territoriais, e os temas relativos ao campo deveriam ser abordados, já que umas 
das principais fontes de renda do nosso município são decorrentes das produções na zona rural.

Logo, este tema não cabe apenas à zona rural ou se há ou não um aluno residente da zona rural na escola. É neste sentido que se pode afirmar que as propostas de temas em relação à educação do campo ou que sobre a realidade da zona rural devem ser abordadas.

Apesar da falta de propostas relativas à educação do campo, não se pode, com isso, querer concluir que o movimento ou suas propostas educacionais dos docentes não sejam válidos, mas os alguns temas como a relação campo-cidade devem ser revistas pelos professores daquela escola porque os mesmos estariam amparados pelos PCNs nesta prática.

Diante do exposto nas nossas análises, salientamos a importância de uma reformulação do PPP a cada dois anos pelo menos, visto que a escola está em constante transformação. Um dos fatos que reforça esta concepção é o fato de que os projetos desenvolvidos atualmente não se fazem presentes dentro do Projeto Político Pedagógico escolar a nova formação curricular que a escola sofreu ao decorrer dos anos.

Refletir, discutir, para a construção de um Projeto Político Pedagógico que supra as necessidades escolares é fundamental para a escola tenha um processo de inclusão dos seus alunos, além de uma reformulação de metodologias visando a um melhor processo de ensino e aprendizagem.

Por fim, reforçamos com esse estudo que a escola pública precisa ser preparada para atender a diversidade cultural dos estudantes sem "apagar" seus rostos e sua cultura. 


\section{Referências}

ALARCÃO, I. Professores reflexivos em uma escola reflexiva.

São Paulo: Cortez, 2003. (Coleção Questões da Nossa Época).

ARROYO, M. G. Currículo, território em disputa. Petrópolis, RJ:

Vozes, 2011.

BRASIL. Programa Nacional de Educação na Reforma Agrária PRONERA: Manual de Operações. Brasília, 2004.

BRASIL. Parâmetros Curriculares Nacionais: Terceiro e quarto ciclos - Matemática. Brasília: Secretaria de Ensino Fundamental, 1998a.

. Parâmetros Curriculares Nacionais: Terceiro e quarto ciclos: apresentação dos temas transversais. Brasília: Secretaria de Educação Fundamental, 1998b.

CONSELHO NACIONAL DE EDUCAÇÃO. Resolução CNE/CEB, $\mathbf{n}$. 1, de 3 de abril de 2002. Institui Diretrizes Operacionais para a Educação Básica nas Escolas do Campo. Disponível em: http://portal.mec.gov.br/cne/arquivos/pdf/CEB012002.pdf. Acesso em: 20 maio 2015.

CALDART, R. S. A escola do campo em movimento. In.:

ARROYO, Miguel Gonzáles; MOLINA, Mônica Castagana (Orgs.)

Por uma educação do campo. Petrópolis: Vozes, 2004.

CAMOZZATO, V. C.; COSTA, M. V. Da pedagogia como arte às artes da pedagogia. Pro-posições, v. 24, n. 3, p. 161-182, set./dez. 2013. Disponível em: http://www.scielo.br/pdf/pp/v24n3/10.pdf. Acesso em: 25 maio 2015.

EGAMI, C. Y. et al. Panorama das Políticas Públicas do Transporte Escolar Rural. 2008. Disponível em: < http://docplayer.com.br/14590590-Panorama-das-politicas-publicasdo-transporte-escolar-rural.html> Acesso em: 25 maio 2015. 
FARIA, A. L. G. Ideologia no livro didático. 14. ed. São Paulo: Cortez, 2002.

FERNANDES, B. M. Diretrizes de uma caminhada. In: KOLLING, Edgar Jorge et al. (org). Coleção Por Uma Educação do Campo, no 04, Brasília, DF: Articulação Nacional Por Uma Educação do Campo, 2002.

FONSECA, J. J. S. Metodologia da pesquisa científica. Fortaleza: UEC, 2002.

GIL, A. C. Como elaborar projetos de pesquisa. São Paulo: Atlas, 2002.

INSTITUTO BRASILEIRO DE GEOGRAFIA E ESTATÍSTICA. Cidades. 2010. Disponível em:

http://www.ibge.gov.br/home/estatistica/populacao/censo2010/tabela s_pdf/total_populacao_rio_grande_do_sul.pdf. Acesso em: 10 maio 2015.

INSTITUTO NACIONAL DE ESTUDOS E PESQUISAS EDUCACIONAIS ANÍSIO TEIXEIRA. Panorama da educação no campo. Brasília: INEP, 2007.

MOREIRA, A. F. B.; SILVA, T. T. (Org.). Currículo, cultura e sociedade. 2. ed. São Paulo: Cortez, 1997.

MUNARIM, A. Os campos da pesquisa em Educação do Campo: espaço e território como categorias essenciais. In: MOLINA, Mônica Castagna. Educação do Campo e pesquisa: questões para reflexão. Brasília: MDA, 2006.

ROESCH, S. M. A. Projetos de estágios e de pesquisa em administração: guia para estágios, trabalho de conclusão, dissertações e estudos de casos. São Paulo: Atlas, 1999.

SACRISTAN, J. G. 0 currículo: uma reflexão sobre a prática. 3 ed. Porto Alegre: ArtMed, 2000. 
SILVA, L. H. et al. A educação no meio rural do brasil: revisão da literatura. In: BOF, Maria Alvana (Org.). A Educação no Brasil Rural. Brasília: INEP, 2006.

SILVA, T. T.da. Documentos de identidade: uma introdução às teorias do currículo. Belo Horizonte: Autêntica, 1999.

SILVA, T. T. da; MOREIRA, A. F. (orgs.). Territórios Contestados: o currículo e os mapas políticos e culturais. Petrópolis, RJ: Vozes, 1995.

SILVA, E. L. da; MENEZES, E. M. Metodologia da pesquisa e elaboração de dissertação. 3 ed. Florianópolis: Laboratório de Ensino à Distância da UFSC, 2001.

VEIGA. I. P. A. Projeto Político-Pedagógico da Escola: uma construção coletiva. In: __ Projeto Político-Pedagógico da Escola: uma construção possível. Campinas: Papirus, 2002.

VERGARA, S. C. Projetos e Relatórios de Pesquisa em Administração. 2. Ed. São Paulo: Atlas, 1998.

VIANA, J. F. de O. Populações meridionais do Brasil: história, organização e psicologia. São Paulo: Companhia Ed. Nacional, 1933. 